\title{
Exploring nursing students' transfer of peripheral venous cannulation from skills centre to the clinical setting
}

\author{
Monika Ravik *1,2, Anton Havnes ${ }^{3}$, Ida Torunn Bjørk ${ }^{1,2}$ \\ ${ }^{1}$ Department of Nursing Science, University of Oslo, Oslo, Norway \\ ${ }^{2}$ Faculty of Health and Social Studies, Telemark University College, Oslo, Norway \\ ${ }^{3}$ Centre for the Study of Professions, Oslo and Akershus University College of Applied Sciences, Oslo, Norway
}

Received: October 14, 2014

Accepted: December 7, 2014 Online Published: December 24, 2014

DOI: $10.5430 /$ jnep.v5n3p59

URL: http://dx.doi.org/10.5430/jnep.v5n3p59

\begin{abstract}
Background: It is assumed that practical skills learned through simulation can be transferred to the clinical setting, but little is known about students' skill performance on real patients after simulation-based learning. The literature shows that newly qualified nurses lack proficiency in skill performance, implying that transfer of learning is challenging. The aim is to explore practical skill transfer from skill centre to clinical setting.

Method: A qualitative descriptive observational study of five undergraduate nursing students practicing peripheral venous cannulation (PVC) in the skills centre and clinical setting. Performances were compared using content analysis.

Findings: There were similarities and differences in the students' performance accuracy in the skills centre and the clinical setting. Many steps were performed correctly, though some were performed incorrectly, and several were not performed or not relevant to perform in either setting. Practicing on a mannequin and on actual patients gave different learning opportunities. Practicing on a mannequin gave the students the opportunity to perform most of the PVC steps even if the vein was missed. When students missed the vein on real patients, they had to terminate the attempt, with no opportunity to perform subsequent steps of the skill.

Conclusion: Low-fidelity simulation was found both to be effective, as it provided familiarity with equipment used in the clinical setting, and inadequate due to lacking opportunity to discern differences encountered in the clinical setting. The simulation must be improved to ensure that students learn what is needed for safe practice on real patients in the clinical setting.
\end{abstract}

Key Words: Learning transfer, Nursing education, Skills centre, Simulation, Low-fidelity, Clinical practice, Outcome measurement, Cannula insertion

\section{Introduction}

A main objective in undergraduate nursing curricula is to educate nurses to perform practical skills that ensure quality and safety in patient care. ${ }^{[1]}$ To increase students' learning, two pedagogical settings are used for skill learning: the clinical skills centre and the clinical setting. Clinical skills centres have been used for several decades to facilitate an optimal environment for practical skills learning. ${ }^{[2]}$ A common learning strategy is to use various forms of simulation. ${ }^{[3]}$ Many resources in terms of time, research and money have been invested in the development of equipment

*Correspondence: Monika Ravik; Email: monika.ravik@usn.no; Address: Høgskolen i Telemark, Postboks 203, N-3901 Porsgrunn, Norway. 
and simulation scenarios. ${ }^{[4]}$ There has always been a general assumption in nursing education that when a practical skill is practised in the skills centre, the student will be more able to perform and develop that skill in the clinical setting.

However, it is well documented that newly qualified nurses lack proficiency in basic practical skills needed for competent nursing care. ${ }^{[5-7]}$ Marshburn et al. ${ }^{[7]}$ claimed in their study that only $8 \%$ of newly qualified nurses were comfortable performing all the skills and procedures needed in a clinical setting. Starting an intravenous line was the skill nurses felt least comfortable in performing. Newly graduated nurses entering the workforce with sub-optimal proficiency contribute to questioning the value of simulation as a learning strategy in nursing education. Lauder, Reynolds \& Angus ${ }^{[8]}$ suggested that nurse educators overlook students' problems in using previously gained knowledge in other similar situations.

\subsection{Simulation-based learning}

Simulation technologies with different levels of fidelity are used in skills centres to imitate or amplify clinical practice. Fidelity refers to the degree that the situation or the object acted upon imitates reality. Low-fidelity simulation involves the use of static mannequins or task trainers with injection sites or internal devices used for insertion of catheters. ${ }^{[2]}$ High-fidelity simulation involves live actors, or patient simulators with vocal and physiological responses to treatment. ${ }^{[3]}$ Low-fidelity simulation is frequently used in learning single practical skills, such as peripheral venous cannulation (PVC) ${ }^{[9]}$ Research in low-fidelity simulation is limited, as most simulation research in nursing education entails high-fidelity simulation. ${ }^{[9]}$

Simulation-based learning is highly appreciated by nursing students. ${ }^{[10-15]}$ Positive learner experiences with simulation, such as increased engagement in learning, ${ }^{[13]}$ decreased levels of anxiety, ${ }^{[12]}$ and satisfaction and self-confidence in learning ${ }^{[15,16]}$ have been reported in several studies. Satisfaction and self-confidence in the skills centre is no guarantee for adequate theoretical and practical competence and appropriate patient outcomes. ${ }^{[17]}$ The significance of simulation-based learning in nursing education is justified by the assumption that, having performed simulation training, students are prepared to perform adequately on actual patients in the clinical setting. ${ }^{[18,19]}$ However, this recommendation is based on participants' perceptions in surveys, interviews, and structured clinical observation in the skills centre setting. There is a need for other ways of exploring the impact of simulation training, particularly as research indicates that students appear to lack capability to judge their own performance, ${ }^{[20]}$ and facilitators tend to be too subjective in their evaluations. ${ }^{[17]}$

A review of the literature identified two studies ${ }^{[21,22]}$ that directly reported on students' skill performance across skills centre and clinical setting. Alteren \& Bjørk ${ }^{[21]}$ investigated if role-play as a learning strategy influenced the skill of helping the patient to eat and drink. Students experienced different but complementary learning opportunities in the two learning environments, and similarities between the two learning settings supported their performance. Kirkman ${ }^{[22]}$ explored how high-fidelity simulation prepared nursing students to perform a respiratory assessment on actual patients. High-fidelity simulation was an effective learning strategy, and students applied what was achieved in the simulation session to actual patients. Kirkman ${ }^{[22]}$ promoted similarity and relevance between the learning settings as a contribution to students' performance in the clinical setting. None of these studies explored the learning process in detail. There is a need for better understanding of factors that influence skill performance in the two pedagogical settings of nursing education. ${ }^{[8,23,24]}$ Previous research ${ }^{[25]}$ calls for observation of actual student performance in the clinical setting after simulation-based learning. In this study, we explore the extent to which students' achievements in the simulation setting also can be observed in the clinical setting. The study also contributes to the understanding of simulation learning by applying theoretical perspectives on transfer of learning.

\subsection{Application of knowledge from one situation to another}

Transfer of learning is defined as the application of knowledge from one particular situation to another, ${ }^{[26]}$ for instance, applying what you have learned in an educational or training setting to a clinical setting. ${ }^{[27]}$ Two claims are made with respect to the transfer issue in psychological and educational literature. (1) Transfer as an empirical claim: the extent to which a skill achieved in one context is applied in another. (2) Transfer as a conceptual claim: how this empirical "matter of fact" or its absence is explained. The conceptual claim implies that there are certain ways of structuring educational settings to increase the probability of transfer of skills and knowledge from one context or task to another. While transfer is central to any educational project, research has shown that transfer in the empirical meaning often is problematic. ${ }^{[27]}$ Transfer of complex skills that involve both manual, cognitive, communicative and relational aspects, such as those we find in nursing, are poorly addressed. ${ }^{[8]}$ There are however, several theories in other disciplines that propose what affects how learning across contexts is explained and supported. To some extent these theories are contrasting. However, they may also be complementary in terms of emphasising diverse aspects of this complicated phenomenon.

\subsubsection{Behaviorist approach}

The behaviorist approach is described as learning taking place through the association of a response with particular stimuli. ${ }^{[28]}$ Thorndike ${ }^{[29]}$ proposed the need for identical elements between different tasks and situations to promote 
transfer of learning. The more similarity between the situation and response across learning settings, the more transfer of learning will occur. A probability that a certain stimulus situation would be followed by a certain response was termed "connectionism". When the connection between a situation and a response is established, students are ready to act, and their learning is effective. "Belongingness" was a central aspect of connectionism, meaning that actions accrued sequentially when a second action was experienced as belonging to the first. ${ }^{[29]}$ Thorndike ${ }^{[29]}$ also proposed that a number of trials and errors before achieving correct behavior provided an advantage in the transfer process.

\subsubsection{Cognitive approach}

The cognitive approach attributes learning to changes in cognitive abilities based on the agent's processing of information. ${ }^{[30]}$ Generating meaning-making and sequential development of an individual's cognitive abilities, such as recalling, analysing, reflecting and understanding is emphasised as learning due to knowledge transferred from short to long term memory. ${ }^{[31]}$ The mind is seen as an information processor, and new information is linked to prior knowledge and logically organised. ${ }^{[31]}$ Bruner $^{[30]}$ emphasised categorisation of information as important in the structuring of knowledge and a prerequisite for learning. Bruner ${ }^{[31]}$ also highlighted general principles on the understanding of patterns as best suited to support transfer of task performance from one context to another. Essential in transfer of knowledge from one context to another is the agent's prior organisation of the information in the long-term memory, and her ability to retrieve that information when appropriate and apply it in the new context.

The cognitive approach to learning has been criticised for being too mentally focused. ${ }^{[32]}$ The learning process could be inhibited if one does not include contextual conditions in the understanding of learning.

\subsubsection{Situated learning approach}

Greeno $^{[32,33]}$ explained learning and transfer from a situated learning perspective. He was inspired by Gibson's ${ }^{[34]}$ concept of affordance, who articulated the relationship between an individual and the environment as a key factor contributing to performance or action. Gibson ${ }^{[34]}$ suggested that available information or characteristics in the environment, not individual conditions, was a starting point for a given action. Learning, in a situated perspective, is both to become attuned to affordances in a social activity and also to become increasingly involved in the practices of a community. ${ }^{[32]}$ It implies that transfer is sustained when the agent can perceive and identify key aspects of a situation and act competently, and a new situation affords similar aspects that are identified by the agent. It means that transfer is an aspect of similarities across contexts as well as the agent's ability to perceive them and act on them according to prior learn- ing. [35]

\subsubsection{Complimentary approach}

In all the learning approaches so far mentioned, identical elements or similarities across tasks and contexts are central to the process of learning transfer. Marton ${ }^{[36]}$ criticizes teaching strategies based only on similarities, arguing that students also have to be exposed to differences in order to connect knowledge between varying situations. Discerning differences appearing in the same learning object gives the student a firm foundation of factual knowledge. ${ }^{[36]}$ Preparing students to see situations in different ways, could develop their abilities to be aware of new or additional aspects of the task; thus, understanding the situation in a wider perspective. In consequence, transfer implies relearning within a new context.

\subsection{Aim and research questions}

This paper is part of a larger study on practical skill learning in nursing education. The present study explores students' mastery of PVC in the skills centre and in the clinical setting, and whether their performance of the procedure is consistent or varies in these two settings. In its details the PVC procedure consists of 47 steps, according to the manual used by the nurse education programme. To be able to compare students' performance at the level of each step in both settings and compare across the settings, the number of participants needs to be restricted. The limited number of students and the details of the analysis underscore the explorative nature of the study.

The following research questions were developed:

- What is the nature of students' performances of PVC: - during low-fidelity simulation in the clinical skills centre?

- on actual patients in a hospital setting after lowfidelity simulation based learning?

- What are the similarities and differences in students' performances of the PVC in the clinical skills centre versus the hospital setting?

\section{Methods}

\subsection{Design}

The present study has a qualitative descriptive observational research design. In order to explore an area where no systematic research was done before, research questions were gradually formulated after we became aware of relevant issues. We formulated research questions that aimed to describe events accurately, and to portray patterns and regularities in the material. ${ }^{[37]}$ 


\subsection{Sample and setting}

The study was performed in two settings: the clinical skills centre and medical hospital wards. An open invitation to participate was given to bachelor in nursing students enrolled in the first semester of year two. Twenty-seven students consented to participate. Nine of these students were included in the main study by random allocation. In the skills centre, the students practised in groups of three, all supervised by the same teacher. The week after skills centre practice, the students entered clinical placement. Each student had a clinical supervisor who was a registered nurse. In the present study a strategic sample was used. ${ }^{[38]}$ Five students were included, based on their similar approach in training of PVC in the skills centre: sole practice on the arm of a static mannequin. No student had previous experience with PVC. The study was performed at a university college in the southern part of Norway and in the hospital that offered clinical placements for the nursing students.

\subsection{Data collection}

Data were collected of students' practice and performance of PVC. PVC is a technical practical skill included in the bachelor curriculum in Norway, as approximately $50 \%$ of the patients in Norwegian hospitals undergo cannula insertion during their stays. ${ }^{[39]}$ Data were collected through observation, which is relevant when the purpose is to collect detailed and comprehensive data in the informants' natural environments. ${ }^{[38]}$ A video-camera was used in both settings. Video-recordings provide extensive data on the students' activities, and provide opportunities for comprehensive analysis by all investigators. ${ }^{[40]}$ Each participant was video-taped during practice in the skills centre (two students practised once on the mannequin; three students, twice). In the hospital, four of the students were video-recorded during their first performance on a patient. Due to practical circumstances, the fifth student was video-recorded during the third performance. A hand-held camera was used to make dynamic recordings. The zoom function allowed the camera to be a distance from the students, aiming to avoid interruptions and to reduce the influences of the camera. A total of thirteen video-recorded performances were analysed in this study (in total 480 minutes; 134 minutes in skills centre and 346 minutes in the clinical setting). Field notes were written to supplement the videos, ${ }^{[38]}$ for example, when students were finding equipment. Reflective notes were written ${ }^{[38]}$ on personal experiences of being a researcher in a setting formerly experienced as a nurse and a teacher. Due to time pressure related to subsequent recordings, some field notes were written at the end of the day.

\subsection{Data analysis}

The visual data in this study was analysed with qualitative content analysis. $^{[41]}$ According to Sandelowski, ${ }^{[41]}$ qualitative content analysis is both data-derived and based on pre-existing coding systems. We began by using an inductive approach, which allows the findings to derive from the raw data without theoretical or conceptual implications. ${ }^{[42]}$ The video-recordings were watched several times to get an impression of the data. Through each new round of watching, we were sensitised to new or nuanced events. In this first phase, we were struck by the many instances of non-performance of several steps of the procedure, and we also started noticing that several steps were performed in a wrong way. The video-recordings were data-rich and difficult to absorb. To acquire a detailed understanding of the performance in both settings, the second phase was deductive and systematic. In line with Sandelowski's ${ }^{[41]}$ suggestions on the use of coding systems, we modified elements in the normative model of practical skill performance ${ }^{[5,43]}$ and existing guidelines for PVC (see Figure 1).

The model of practical skill performance encompasses six elements necessary for good practical skill performance: substance, sequence, accuracy, fluency, integration and caring comportment. ${ }^{[5]}$ In this study, we focused on the first three elements. Substance and sequence of a skill should be performed as decided by procedural guidelines, and accuracy refers to correct and precise steps in performance. The substance and sequence of PVC were operationalised into 47 steps based on the electronic program Practical Procedures in Nursing ${ }^{[44]}$ (see Figure 1), and implemented as a coding scheme into a software program developed for this study. Each of the steps $(47 \times 5$ students $\times 2$ learning environments $=$ in total 470 steps $)$ in the practical skill performances was coded for their accuracy, "correct performance", "incorrect performance" or "not performed". The students who practised twice in the skills centre we credited with correct performance if it occurred either in the first or second try. We also used "not relevant", "missed opportunity" and "cannot assess" as codes (see Figure 1). Each sequence was coded from 1-47 as the steps were performed. The software solution stored the data in a relational database, organised the data into tables and linked them together based on defined relationships. ${ }^{[45]}$

After identifying the accuracy and sequential presentation of students' performance at each step of the practical skill in both skills centre (235 steps) and clinical setting (235 steps), we assembled procedural steps that concerned the same content into six categories (see Figure 2), for easier representation of patterns in the data. These categories are easily recognized by students, nurses and nursing teachers.

To enhance the analysis, we have used numbers in the generation of meaning about the different qualities in the students' skill performances. ${ }^{[37]}$ Within each category we counted and summarised the codes of accuracy into patterns of performances across all students. In the last phase of the analysis we compared, contrasted and described, within each category, each student's performance in both learning settings to identify similarities and differences in accuracy. 


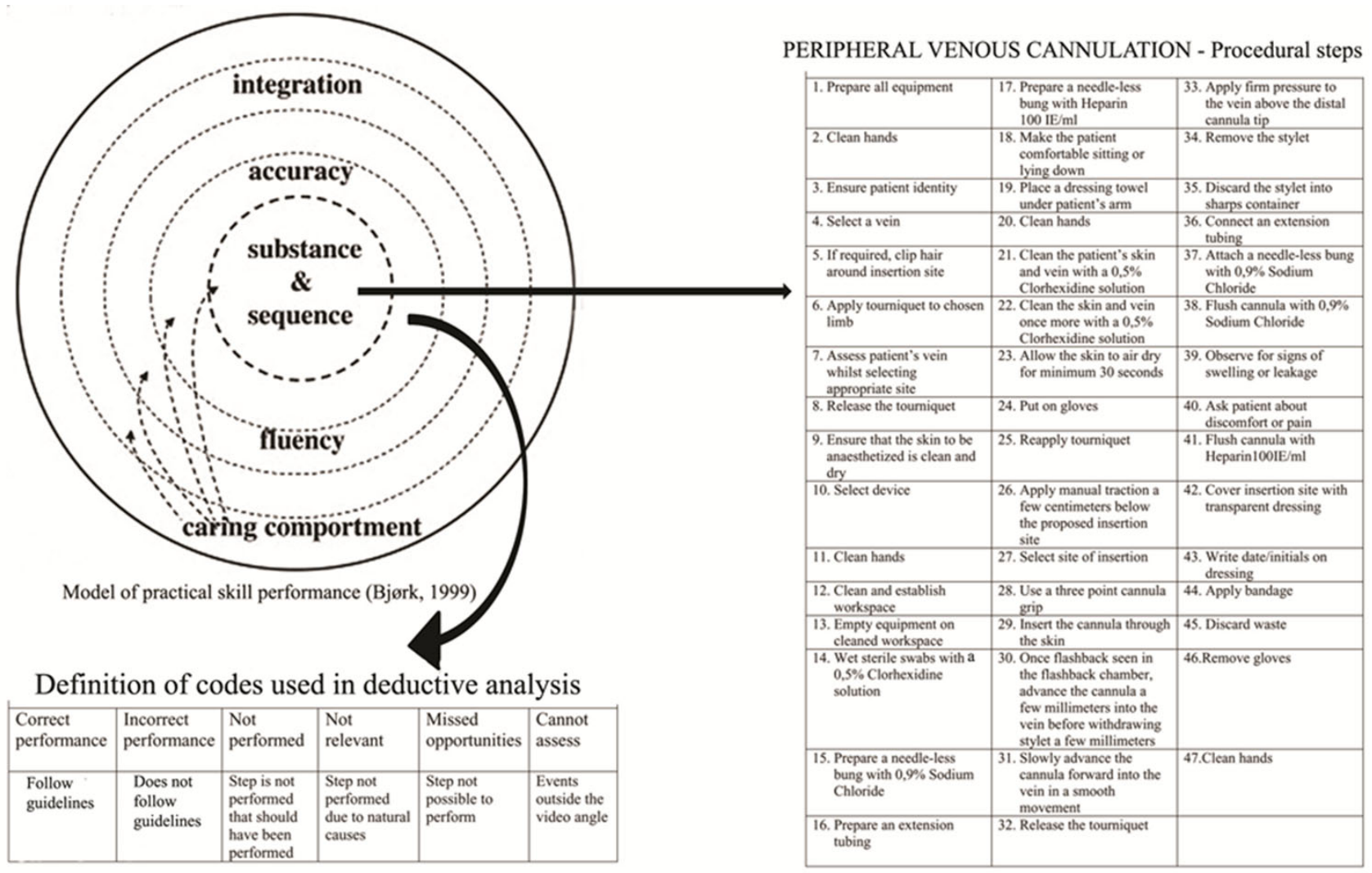

Figure 1: Theory and codes underlying the deductive phase of the data analysis

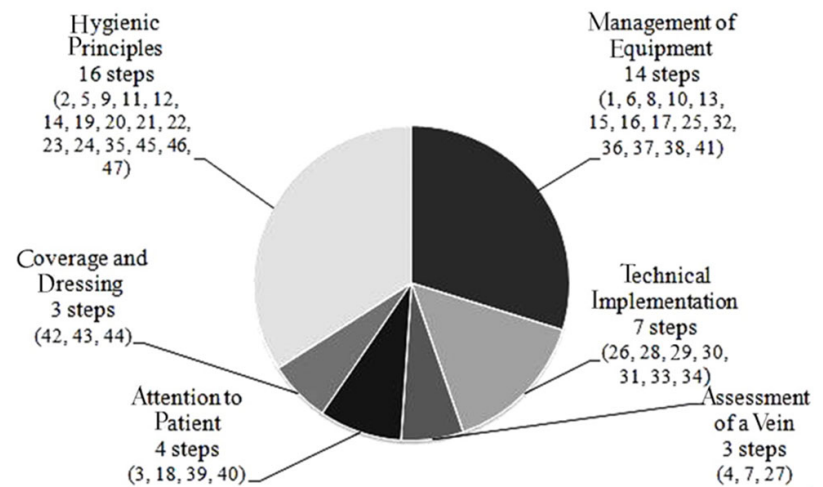

Figure 2: Six categories of PVC content with number of procedural steps in each category

\subsection{Ethical considerations}

The research was performed according to the ethical principles in the Declaration of Helsinki. ${ }^{[46]}$ The study was approved by the Norwegian Social Science Data Service and, the University College and hospital involved. All the participants received oral and written information before data collection. Informed consent was obtained from nursing students, supervisor in the clinical skills centre, patients and registered nurses who were video-taped. The patients' faces were not video-recorded to secure anonymity. All the participants were free to withdraw at any time without giving any form of explanation. Participants were informed that the researcher would not supervise during performance. Students' performance during video-recordings would not influence assessment during skills centre practice or clinical placement. The participants were informed that only the research team had access to the video-recordings.

\section{Results}

In this section we first present results from the students' practice of PVC in the skills centre, followed by results from the students' practice in the clinical setting. To illuminate these results, we have used numbers to show the distribution of steps in each code of accuracy. In the last part of the results, we compare patterns in students' performances in the two learning settings to describe the concept of transfer of learning. Numbers in brackets refer to steps of the procedure.

\subsection{Practicing PVC in the skills centre}

\subsubsection{Correct performance}

Correctly performed steps comprised 143 of 235 steps of the PVC (see Figure 3). 


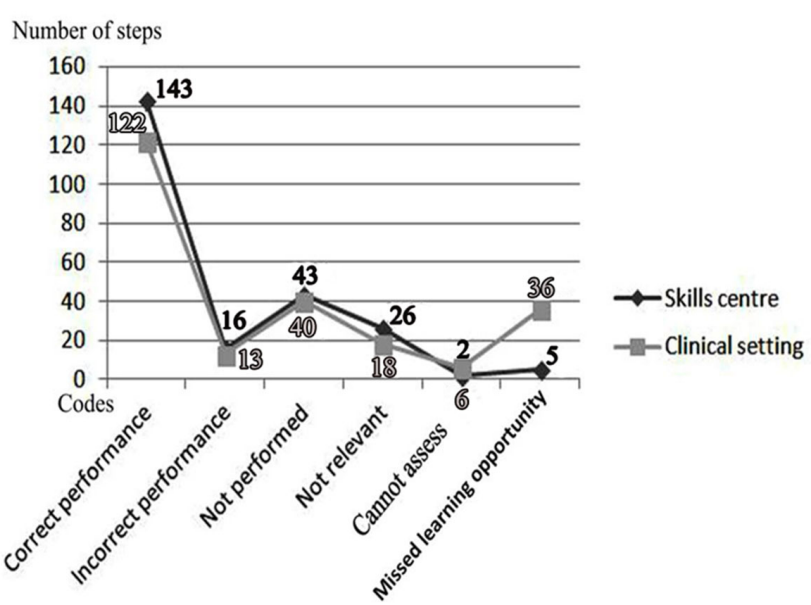

Figure 3: A distribution of students' performed steps of PVC in the skills centre and in the clinical setting according to codes of accuracy

Many of these steps belonged to the category Management of Equipment. All the students correctly performed steps concerning preparation of equipment and tourniquet handling $(1,6,8,13,25,32)$. All the students correctly assessed and selected a vein $(7,27)$ in the category Assessment of a Vein. In the category Technical Implementation, four of the students traced the skin and all students inserted the cannula in a correct angle $(26,29)$ while four students handled the cannula and stylet correctly $(28,34)$. In the category Hygienic Principles, which included the largest number of steps, all students correctly performed steps concerning cleaning hands, glove use and disposal of the stylet in a sharps container $(2,24,35,46,47)$. Four of the students cleaned their hands $(11,20)$ during the skill performance (Steps are labelled in Figure 1).

\subsubsection{Incorrect performance}

Incorrectly performed steps comprised 16 of 235 steps of the PVC (see Figure 3). In the category Management of Equipment, one student contaminated the extension tubing with the integrated stop cock and forgot to close the stop cock before connecting it to the patient after flushing (16, $36)$. In the category Technical Implementation, one student used a wrong three- point cannula grip (28); and in the category Coverage and Dressing, one student attached the transparent dressing far below the cannula cap (step 42). In the category Hygienic Principles three students just pretended to clean the mannequin's skin (21).

\subsubsection{Not performed}

Steps not performed comprised 43 of 235 steps of the PVC (see Figure 3). In the category Management of Equipment, two students did not prepare and attach the extension tubing $(16,36)$. In the category Technical Implementation, four of the students performed the crucial step of advancing the cannula slightly to ensure entry into the vein's lumen af- ter the first flashback of blood in the chamber of the stylet (30). In the category Attention to Patient, four of the students did not identify the "patient" by name and birthdate (3), and none of the students observed for swelling or leakage at the site of insertion (39) or checked for discomfort or pain when the cannula was flushed (40). In the category Coverage and Dressing, none of the students applied a dressing to stabilise and protect the PVC (44). In the category Hygienic Principles, only the first student cleaned the workspace (12) and twice cleaning of the "patients" skin (22) was only performed by one student.

\subsubsection{Not relevant to perform}

Steps not relevant to perform comprised 26 of 235 steps (see Figure 3). In the category Management of Equipment, preparing and flushing the cannula with Heparin (17, 41) was not relevant, as Heparin was not available in the skills centre. In the category Attention to Patient, it was not relevant to make the "patient" comfortable (18), as the arm/mannequin was appropriately positioned during the whole procedure. In the category Hygienic Principles, students could not clip hair around the insertion site or check if the skin at the site of anaesthetization was clean and dry $(5,9)$ as the plastic arm lacked hair and anaesthetics were not available. The dressing towel under the arm was not changed between students' performances (19).

\subsubsection{Missed opportunities}

Missed learning opportunities comprised 5 of 235 steps (see Figure 3 ). This concerned a lack of options to select a suitable device (10) since there was only one particular device to be had. In Figure 4, we have summarised the coding of the students' performance of PVC in the skills centre.

Figure 4 shows the distribution of the students' performance of steps in a total of 5 performances of PVC.

\subsection{Performing PVC in the clinical setting}

\subsubsection{Correct performance}

Correctly performed steps comprised 122 of 235 steps of the PVC (see Figure 3). As in the skills centre, many of these steps belonged to Management of Equipment (1, 13, 25, 32) and concerned handling the equipment and tourniquet. All the steps $(4,7,27)$ in Assessment of a Vein were correctly performed by all students. In Technical Implementation, all the students correctly inserted the cannula through the skin (29), while three students traced the skin (26) and used a three-point cannula grip (28). All the students removed the stylet correctly (34). Only one student advanced the cannula slightly to ensure entry into the vein's lumen (30). In Hygienic Principles, all students immediately disposed the stylet into a sharps container (35), and four of the students disinfected their hands at three of the four recommended steps of the procedure $(11,24,46)$. 


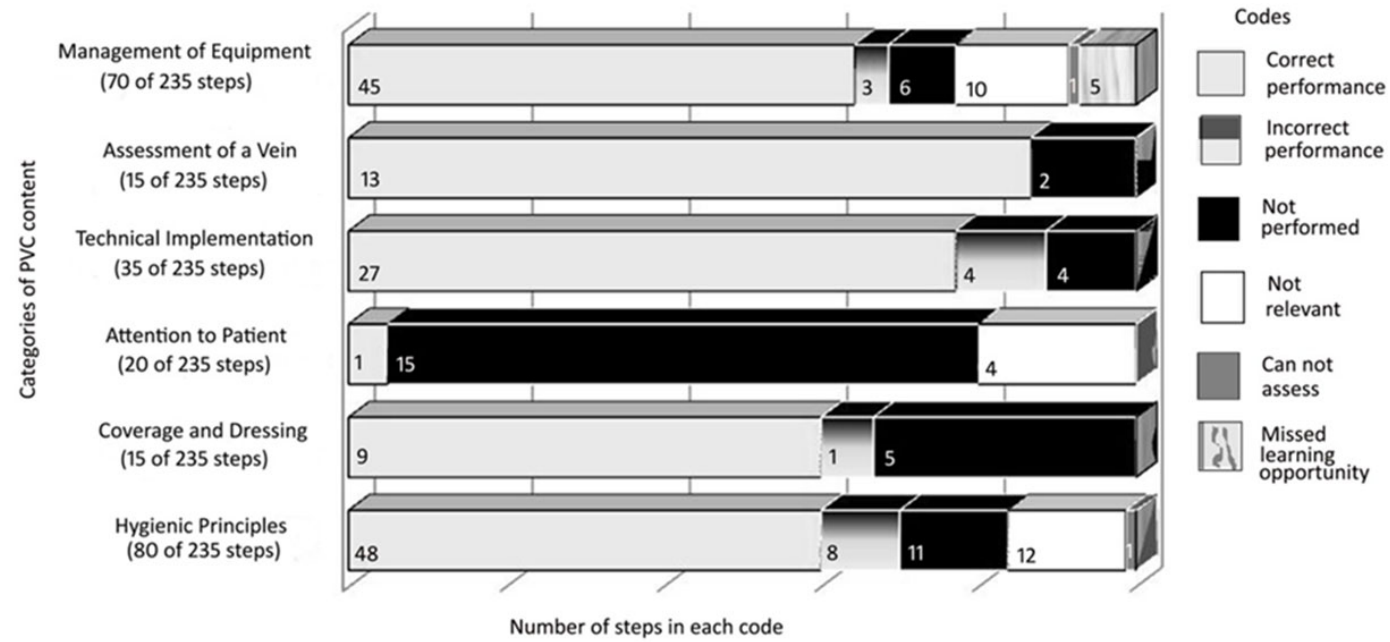

Figure 4: Distribution of students' performed steps in 5 attempts of PVC in the clinical skills centre (relative differences within each column)

\subsubsection{Incorrect performance}

Incorrectly performed steps comprised 13 of 235 steps (see Figure 3). In Technical Implementation, two students used an incorrect three-point grip on the cannula (28). In Coverage and Dressing, another student attached the transparent dressing far below the cannula cap (42). In Hygienic Principles, two students used back- and-forward movements instead of circular movements when cleaning the patients' skin (21).

\subsubsection{Not performed}

Steps not performed comprised 40 of 235 steps (see Figure 3). During Management of Equipment, two of the students did not prepare an extension tubing (16). In Technical Implementation, two students did not advance the cannula slightly to ensure entry into the vein's lumen (30). In Attention to Patient, no student identified the patient by name and birthdate (3), and three of the students did not make the patient comfortable (18). In Hygienic Principles, four students did not use a dressing towel under the patient's arm (19), and three students did not clean the skin twice (22). The guidelines specify using an antiseptic agent to clean hands at four steps in the procedure $(2,11,20,47)$. One student never used an antiseptic agent to clean her hands or used gloves, and the other students cleaned their hands three out of four times. Only two of the students cleaned the workspace thoroughly with $70 \%$ alcohol (12).

\subsubsection{Not relevant to perform}

Steps not relevant to perform comprised 18 of 235 steps of the steps (Figure 3). In Management of Equipment two students did not prepare Heparin or flush the cannula with Heparin $(17,41)$ because an infusion was administered after insertion. It was not relevant for students to clip hair around the insertion site or check if the skin at the site of anaesthetisation was clean and dry $(5,9)$ in Hygienic Principles because the patients did not have hair on their arms and no anaesthetics were needed.

\subsubsection{Missed opportunities}

Missed learning opportunities occurred in 36 of 235 steps (see Figure 3). When students missed the vein, as three of the students did this first time, they had to terminate the PVC. Subsequent steps related to almost all of the categories of the PVC were therefore not performed. Missing the vein resulted in the following: In Management of Equipment, students could not use any of the equipment related to the use of extension tubing, sodium chloride or Heparin (36, 37, 38, 41). In Technical Implementation, students lost the opportunity to practise the crucial step of advancing the cannula slightly to ensure entry into the vein's lumen (30). Students also missed learning opportunities related to Attention to Patient such as observing for swelling or leakage and asking about discomfort or pain $(39,40)$. No performance was possible of any of the steps related to Coverage and Dressing $(42,43,44)$. In Figure 5, we have summarised the coding of the students' performance of PVC in the clinical setting.

Figure 5 shows the distribution of the students' performances of steps in a total of 5 performances of PVC.

\subsection{Similarities and differences between the skills centre and the clinical setting}

In this paragraph, we summarize and describe the major similarities and differences seen in the skills centre and the clinical setting. In Figure 6, we show how many of the steps in each category of accuracy were similarly performed in the clinical setting after practice in the skills centre, 140 of 228 steps (We use 228 (235-7) steps in our comparison be- 
cause 7 steps that should have been performed in the skills centre were categorised as missed or cannot assess).

In general, students were able to perform more steps of the procedure in the simulation setting than in the clinical setting. Figure 6 also shows that students performed more steps both correctly and incorrectly in the skills centre compared to the clinical setting. More steps were also not performed and not relevant to perform in the skills centre than in the clinical setting.

Of the 143 correctly performed steps in the skills centre, 103 steps were also performed correctly in the clinical setting (see Figure 6). These steps were seen in the categories Management of Equipment (preparing equipment and management of the tourniquet), Assessment of a Vein (assessment of a vein and site of insertion), Technical Implementation (management of- and inserting the cannula through the skin and vein), and Hygienic Principles (cleaning hands and disposal of the stylet). Of the 16 incorrectly performed steps in the skills centre, 7 steps were also performed incorrectly in the clinical setting (see Figure 6). These steps were seen in the category Hygienic Principles (cleaning the patients' skin), Technical Implementation (three-point cannula grip) and Coverage and Dressing (cover of insertion site). Of the 43 steps that were not performed in the skills centre, 17 steps were also not performed in the clinical setting (see Figure 6). These steps belonged to the categories Technical Implementation (advancing the cannula into the vein before withdrawing the stylet), Attention to Patient (ensure patient's correct identity), and Hygienic Principles (twicecleaning of patients' skin). Of the 26 steps that were not relevant to perform in the skills centre, 13 steps were not relevant to perform in the clinical setting (see Figure 6). These steps concerned the categories Management of Equipment (management of Heparin 100IE/ml) and Hygienic Principles (hair removal and anaesthetization).
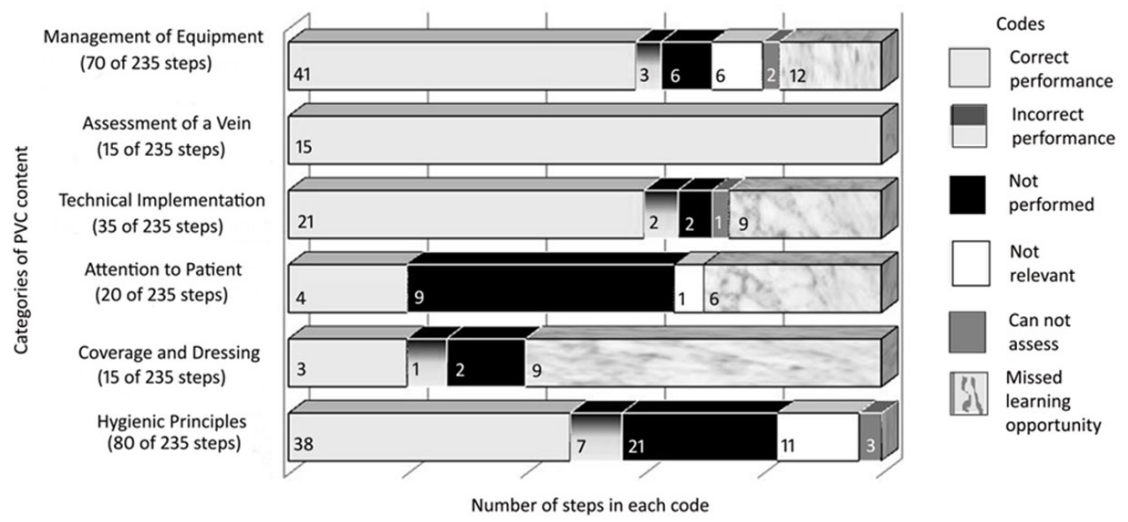

Figure 5: Distribution of students' performed steps in 5 attempts of PVC in the clinical setting (relative differences within each column)

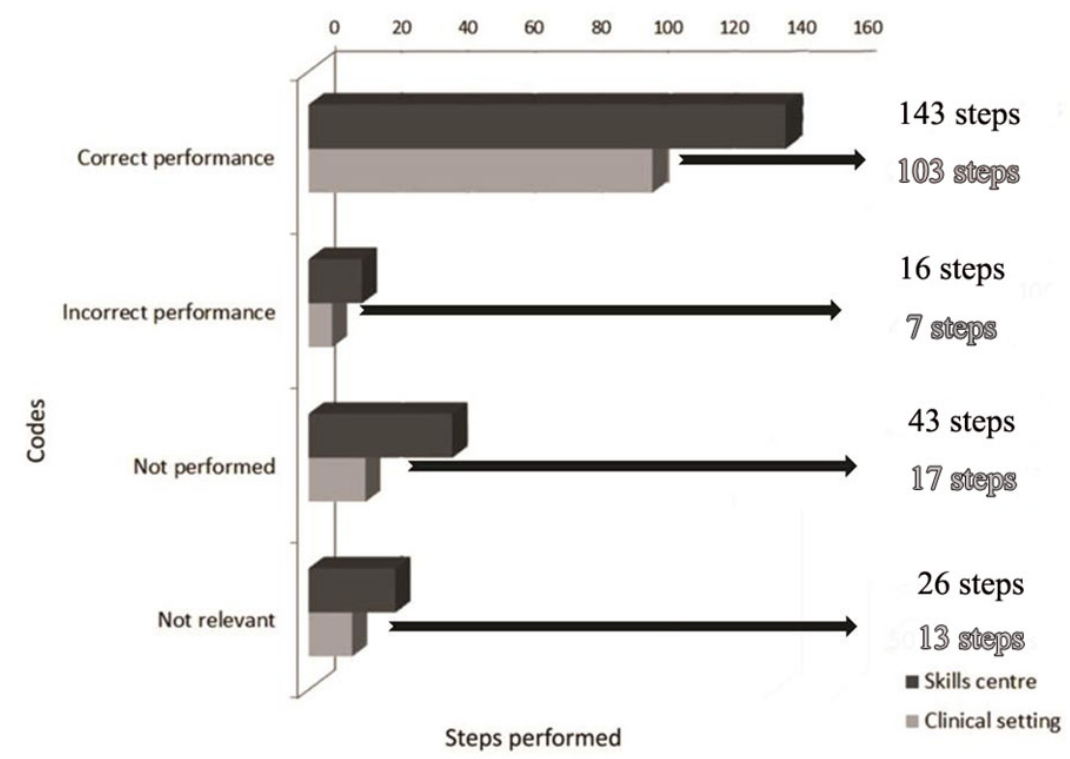

Figure 6: Performance of similar steps in the skills centre and the clinical setting 
The differences in numbers of performed steps in the two learning settings are mostly related to missed learning opportunities in the clinical setting. Three students missed the vein and had to terminate the cannulation, thereby losing the opportunity to perform steps in most categories of the PVC. We cannot know if they would have performed these steps correctly, incorrectly or not at all. Adding to the difference in numbers of performed steps is also the fact that students in the clinical setting failed to clean their hands at some of the recommended steps of the procedure.

\section{Discussion}

In this study students performed a large number of PVC steps correctly across both learning settings, and many of these steps concerned Management of Equipment. In the clinical setting students were immediately familiar with the equipment they had used in the skills centre such as the tourniquet, the venous cannula, gloves and the needle-less bunges. Houghton et al. ${ }^{[47]}$ highlighted common equipment used in both learning settings as an advantage in linking what was previously achieved to a new situation. Thorndike ${ }^{[29]}$ referred to learning as a process of forming associations, and it is plausible to interpret the students' experiences of familiarity with identical elements across learning settings as a strengthening of this process. In a study by James and Chapman, ${ }^{[48]}$ familiarity seemed to be very important when students undertook their first clinical practices in an acute placement. Students were met with many disorienting and often serious events. Experiencing familiarity between task elements and setting enabled students to perform tasks in the new learning situation.

Some of the steps of the PVC performance were performed correctly despite apparent differences in conditions or appearances of the mannequin versus patient arms, such as assessing the veins. The arm of the mannequin had inflexible veins and skin made of rubber, and was completely different from any arm the students experienced in the clinical setting. The mannequin had several pre-marked puncture sites as well as specially developed and visible veins, and the students could not doubt where the venous cannula was to be inserted. In contrast, patients' veins are often invisible, rolling or not palpable. ${ }^{[4]}$ Correct performance despite differences is not supported by Thorndike's ${ }^{[29]}$ theory of identical elements. These findings resonate more with views on learning and transfer within a situated learning perspective. ${ }^{[32,35]}$ In this perspective, transfer is contingent on the learner's attunement to affordances in the learning situations. In the skills centre the students could just insert the needle without thinking or manipulating the mannequin's skin. In the clinical setting, they encountered soft skin and veins that looked and were positioned differently. This required assessing through touching, checking and choosing the most appropriate vein. Students were provided with new information and constructed knowledge by interacting with the information that appeared in the clinical environment. ${ }^{[32,35]}$ Alteren \& Bjørk $^{[21]}$ noted similar findings in their study of students practising to give food and drink to patients. Feeding real patients was viewed as more complex than feeding fellow students due to the patients' communication problems. Students still reported that they succeeded in feeding because they were alerted and attuned to other signs from the patients. For example, when the patient made a sign with his hand, a student correctly interpreted this as a request for more food.

Students in our study also performed some PVC steps incorrectly in both learning settings; in other words, they transferred inappropriate knowledge. These steps mainly concerned Hygienic Principles, for example, cleaning the patients' skin before the cannula insertion (step 22). Making errors during performance is viewed as helpful in the learning process, ${ }^{[29,50]}$ but this learning by error is contingent upon students being made aware of their errors. Students in the study by Helyar et al. ${ }^{[50]}$ experienced that information about errors during simulation of medication administration helped them to avoid making the same errors in the clinical setting. Students in our study continued to perform incorrectly in the clinical setting, and based on videorecordings, we know that the students in question were not made aware of their errors during training. This begs consideration of the students' cognitive approach in the learning process. The theory of identical elements does not focus on cognition as an aspect of successful transfer processes, but on identical elements as the linkage in acting between different learning settings. ${ }^{[51]}$ This may demonstrate that transfer of skill performance only based on identical elements is a mechanical approach, ${ }^{[52]}$ where prior performed actions, regardless of their quality, trigger the same performance in a new situation. A didactic learning approach only based on identical elements may deactivate the learner. We do not suggest rejecting the explanatory power of the identical element in understanding learning across contexts. However, to some extent it might be the contextualised conditions and not the learner's efforts that underlie performance. We consider practical nursing skills as complex actions and have used the normative model of practical skill performance ${ }^{[43]}$ in our judgment of students' skill performance. This complexity requires that students use their cognitive abilities to be attentive to the patient and to analyse and reflect on their own actions. Previous research has stated that reflective and analytical skills are necessary in connecting knowledge between school and practice. ${ }^{[31,53]}$ When that is missing, it is understandable that students transfer incorrect skill performance.

Common guidelines ${ }^{[44]}$ were used across the learning settings. A logical assumption would be that this similarity would enhance students' performance in the clinical setting. Rather unexpectedly we found a great variation in how students followed these guidelines. Although 
the guidelines were sequentially organised and might offer what Thorndike ${ }^{[29]}$ labelled "belongingness", the students skipped steps at several places in the procedure. Disinfection of the place of insertion was poor and according to Malach, ${ }^{[54]}$ this is a common reason for infection. A dramatic consequence occurred when the students did not advance the cannula before removing the stylet (step 30), as this caused them to miss the vein. Steps not conducted resulted in a sequential breach ${ }^{[29]}$ and constrained students' skill performance. These breaches had no consequences when they performed the skill on a mannequin, but had notable consequences in the clinical setting such as poor hygiene and lack of care and safety precautions. We can only speculate on the reasons for skipping procedural steps. Are the guidelines too detailed, thereby creating overload as students try to memorize the steps, or is there a lack of guidance in the learning process? Is it enough just to have guidelines or must the students be taught how to discriminate between the importance of the different steps, to go beyond the detailed steps and gain deeper understanding of skill performance ${ }^{[55]}$ ?

We found that practising the procedure in the clinical setting was contingent on a successful cannula insertion. If the vein was missed, students had to terminate their attempt and had no opportunities to recall and perform what they previously had achieved in the skills centre. Missed learning opportunities in the clinical setting is not a novel finding, and is congruent with results of a previous study that explored students' skill performances during clinical placement. ${ }^{[47]}$ Houghton et al. ${ }^{[47]}$ found that missed learning opportunities were influenced by contextual conditions, as nursing students were not included in medication rounds. Our study revealed that students lacked proficiency in skill performance. We cannot see that contextual conditions can explain why unsuccessful cannulation and missed learning opportunities occurred. We know from earlier research by Marshburn et $a l .{ }^{[47]}$ that nurses found PVC to be the most challenging of all practical skills when they entered practice after education. However, Marshburn et al. ${ }^{[7]}$ did not explore the reasons for this. In the present study, the video-recordings revealed that Technical Implementation was complex and crucial to succeeding with the skill performance.

In the present study, performance on the mannequin provided the students with the opportunity to perform most of the PVC steps because they could continue to practise even if the vein was missed. There was a lack of realism in the simulation because students in the training situation insufficiently experienced critical procedural aspects that they later encountered in the clinical setting. The plastic arm did not qualitatively represent real patients' veins, and the students were not alerted to differences related to Technical Implementation. Simulation practice did not prepare students sufficiently to act within the context and conditions of the clinical setting; for example, the antiseptic was placed by the door and not on the patient's nightstand, meaning that students had to leave the patient's bed to clean their hands during the procedure. Even though nursing education champions the idea of simulation that represents the environment and its equipment, ${ }^{[56]}$ the accurate representation of real clinical skill performance is challenging. As demonstrated in both our study and the study by Alteren \& Bjørk, ${ }^{[21]}$ moving from one learning setting to another does not involve simple transfer of prior skills. Students in Mansour's ${ }^{[57]}$ study experienced similar difficulties. They felt that skills taught at the university were simplistic and did not take into account the contextual differences in the clinical setting. Marton ${ }^{[36]}$ argued that differences in learning situations must be accurately and fully recognised by the learner in preventing transfer problems. The awareness of such potential differences might support learning across contexts because we can expect that in situations will vary. This is consistent with Dzioba et al. ${ }^{[58]}$ who reasoned that educators have to implement reflective activities in the simulation to increase learning. Students have to perceive and distinguish aspects in the learning situation to make sense of issues that will be encountered in new situations. Educators must assist students in this process.

\section{Conclusion}

The findings in this study provide a comprehensive insight into students' actual skill performance in skills centre and clinical setting, as well as contextual aspects that seem to influence their transfer of skill performance. Low-fidelity simulation contributed to experience in skill performance and familiarity with equipment used in the clinical setting. However, the simulation training lacked realism and impeded students' skill performance on real patients. The nature of our findings suggest that simulation as a learning strategy should be improved to ensure that students achieve what is needed for safe practice on real patients in the clinical setting. Students must be prepared for and learn to read situations and tasks as they occur in the clinical setting, such as critical events that could vary when attending to real patients. The present study is the first to detail students' performances as they try to transfer a practical skill from simulation training to performance in the clinical setting. There are, therefore, a broad spectrum of issues that need to be investigated in the future, for example, skill development during the course of a clinical placement, the role of supervision through skill achievement in both learning settings, and skill performance on real patients after skill training on fellow students.

\section{Methodological considerations}

This study only included five students. However, the use of video-supported observation supplied a large amount of data that may have increased the accuracy of the study. By filming the students in the clinical setting directly after their 
practice in the skills centre, we had a unique opportunity to illuminate the similarities and differences in the students' performance of a practical skill across two learning settings. Video-recordings do not represent reality, as the observation is controlled by the researcher, and may be perceived and interpreted differently by various individuals. We are aware that the presence of a researcher with a video camera could be experienced as distracting, or constrain the students' in their skill performances. The methodological quality of the research is both strengthened and weakened by the main researcher's familiarity in both research settings. Familiarity contributed to a detailed observation, parallel with the risk of exploring and understanding the field as a professional and not as a researcher. In order to strengthen the validity of the study, the whole research team was involved in the process of analysis.

\section{Acknowledgements}

We would like to thank all the nursing students, teacher, qualified nurses and patients who participated in the study. This study received funding from the Norwegian Nurses Association, Norway, grant no. 12/0045.

\section{Conflicts of Interest Disclosure}

The author declares that there is no conflict of interest statement.

\section{References}

[1] Bland AJ, Topping A, Wood B. A concept analysis of simulation as a learning strategy in the education of undergraduate nursing students. Nurse Education Today. 2011; 31: 664-670. http: //dx.doi.org/10.1016/j.nedt.2010.10.013

[2] Nehring WM, Lasley FR. Nursing simulation: A review of the past 40 years. Simulation \& Gaming. 2009; 40(4): 528-552. http: //dx.doi.org/10.1177/1046878109332282

[3] Grady JL, Kehrer RG, Trusty CE, et al. Learning nursing procedures: the influence of simulator fidelity and student gender on teaching effectiveness. Journal of Nursing Education. 2008; 47(9): 403-408. http://dx.doi.org/10.3928/01484834-200 80901-09

[4] Lynagh M, Burton R, Sanson-Fisher R. A systematic review of medical skills laboratory training: where to from here? Medical Education. 2007; 41: 879-887. http://dx.doi.org/10.1111/j.136 5-2923.2007.02821.x

[5] Bjørk IT. Practical skill development in new nurses. Nursing Inquiry. 1999; 6(1): 34- 47. http://dx.doi.org/10.1046/j.1440-180 $0.1999 .00005 . x$

[6] Hilton P, Pollard C. Supporting clinical skills developments. Nursing Standard. 2004; 18(35): 31-36. PMid:15160454 http://dx.d oi.org/10.7748/ns2004.05.18.35.31.c3608

[7] Marshburn DM, Engelke MK, Swanson MS. Relationships of new nurses' perceptions and measured performance-based clinical competence. The Journal of Continuing Education in Nursing. 2009; 40(9): 426-432. http://dx.doi.org/10.3928/00220124-200 90824-02

[8] Lauder W, Reynolds W, Angus N. Transfer of knowledge and skills: some implications for nursing and nurse education. Nurse Education Today. 1999; 19: 480-487. PMid:10693496 http://dx.doi.org /10.1054/nedt.1999.0338

[9] Ross JG. Simulation and psychomotor skill acquisition: a review of the literature. Clinical Simulation in Nursing. 2012; 8: 429-435. http://dx.doi.org/10.1016/j.ecns . 2011.04.004.

[10] Flo J, Flaathen, EK, Fagerström, L. Simulation as a learning method in nursing education - a case study of students' learning experiences during use of computer-driven patient simulators in preclinical studies. Journal of Nursing Education and Practice. 2013; 3(8): 138-148. http://dx.doi.org/10.5430/jnep.v3n8p138

[11] Hope A, Garside J, Prescott S. Rethinking theory and practice: preregistration student nurses experiences of simulation teaching and learning in the acquisition of clinical skills in preparation for practice. Nurse Education Today. 2011; 31: 711-715. http://dx.doi . org $/ 10.1016 / j$.nedt . 2010.12.011
[12] Murray C, Grant MJ, Howarth ML, et al. The use of simulation as a teaching and learning approach to support practice learning. Nurse Education Practice. 2008; 8: 5-8. http://dx.doi.org/10.1016 /j.nepr.2007.08.001

[13] Disler RT, Rochester SF, Kelly MA, et al. Delivering a large cohort simulation - beginning nursing students' experience: A pre-post survey. Journal of Nursing Education and Practice. 2013; 3(12): 133142. http://dx.doi.org/10.5430/jnep.v3n12p133

[14] Stirling K, Smith G, Hogg G. The benefits of a ward simulation exercise as a learning experience. British Journal of Nursing. 2012; 21(2): 116-122. http://dx.doi.org/10.12968/bjon.2 012.21 .2 .116

[15] Tosterud R, Hedelin B, Hall-Lord M. Nursing students' perceptions of high- and low- fidelity simulation used as learning methods. Nurse Education in Practice. 2013; 13: 262-270. http://dx.doi . org/10.1016/j.nepr.2013.02.002

[16] Martins JCA, Baptista RCN, Coutinhol VRD, et al. Theoretical and simulation classes in the emergency nursing curriculum in Cape Verde: effect on the self-confidence to intervene in emergencies. Journal of Nursing Education and Practice. 2014; 4(8): 26-33. http://dx.doi.org/10.5430/jnep.v4n8p26

[17] Schrinnick MA, Woo MA, Mentes JC. Human patient simulation: state of the science in prelicensure nursing education. Journal of Nursing Education. 2011; 50(2): 65-72. http://dx.doi.org/1 0.3928/01484834-20101230-01

[18] Feingold CE, Calaluce M, Kallen MA. Computerized patient model and simulated clinical experiences: evaluation with baccalaureate nursing students. Journal of Nursing Education. 2004; 43(4): 156163. PMid: 15098909

[19] Maginnis C, Croxon L. Transfer of learning to the nursing clinical practice setting. The International Electronic Journal of Rural and Remote Health Research, Education, Practice and Policy. 2010; 1-6.

[20] Regehr G, Eva K. Self-assessment, self -direction, and the selfregulating professional. Clinical Orthopaedics and Related Research. 2006 Aug; 449: 34-38. http://dx.doi.org/10.1097/0 1.blo.0000224027.85732.b2

[21] Alteren J, Bjørk IT. [Students' learning of practical skills in the skills-laboratory and the clinical setting; an explorative study] Studentenes læring av praktiske ferdigheter i modellavdelingen og klinikken; en utforskende studie. Vård i Norden 4/2006; 26(4): 2530.

[22] Kirkman TR. High fidelity simulaion effectiveness in nursing students ${ }^{6}$ transfer of learning. International Journal of Nursing Education Scholarship. 2013; 10(1): 1-6. http://dx.doi.org/10.15 15/ijnes-2012-0009

[23] Handley R, Dodge N. Can simulated practice learning improve clinical competence? British Journal of Nursing. 2013; 22(9): 
529-535. PMid:23819196 http://dx.doi.org/10.12968/bjon .2013 .22 .9 .529

[24] Norman J. Systematic review of the literature on simulation in nursing education. The ABNF Journal. 2012: 24-28. PMid:22774355

[25] Tschannen D, Aebersold M, McLaughlin E, et al. Use of virtual simulations for improving knowledge transfer among baccalaureate nursing students. Journal of Nursing Education and Practice. 2012; 2(3): 15-24. http://dx.doi .org/10.5430/jnep.v2n3p15

[26] Beach, K. Consequential transitions: a sociocultural expedition beyond transfer in education. 1999; 24: 101-139. http://dx.doi.o $\mathrm{rg} / 10.3102 / 0091732 \times 024001101$

[27] Detterman DK, Sternberg RJ. Transfer on trial: intelligence, cognition and instruction: Norwood (NJ). Ablex Publishing Corporation; 1993.

[28] Greeno JG, Collins AM, Resnick LB. Cognition and learning. In: Berliner DC, Calfee,(editors). Handbook of Educational Psychology. New York: MacMillan.

[29] Thorndike EL. Human learning: Cambridge (MA). The M.I.T Press; 1931. PMid:16577399 http://dx.doi.org/10.1037/11243-0 00

[30] Bruner J. Acts of meaning. Cambridge (MA): Harvard University Press: 1990.

[31] Bruner J. The process of education. Cambridge (MA): Harvard University Press: 1977.

[32] Greeno JG. Gibson's affordances. Psycological Review. 1994; 101(2): 336-342. http://dx.doi.org/10.1037/0033-295X. 101.2 .336

[33] Greeno JG. The Situative of knowing, learning, and research. American Psychologist. 1998; 53(1): 5-26. http://dx.doi.org/10. 1037/0003-066X.53.1.5

[34] Gibson JJ. The theory of affordances. In Shaw R and Bransford J, (editors). Perceiving, acting, and knowing. Hillsdale (NJ): Erlbaum:1977.

[35] Greeno JG, Smith DR, Moore JL. Transfer of situated learning. In: Detterman DK, Sternberg RJ, (editor). Transfer on trial: intelligence, cognition and instruction. Norwood (NJ): Ablex Publishing Corporation; 1993. PMid:7683033

[36] Marton F. Sameness and difference in transfer. The Journal of the Learning Sciences. 2006; 15(4): 499-535. http://dx.doi.org/1 $0.1207 / \mathrm{s} 15327809 \mathrm{j} 1 \mathrm{~s} 1504 \_3$

[37] Sandelowski M. Focus on research methods. Real qualitative researchers do not count: The use of numbers in qualitative research. Research in Nursing \& Health. 2001; 24: 230-240. PMid:11526621 http://dx.doi.org/10.1002/nur.1025

[38] Polit DF, Beck CT. Essentials of nursing research: appraising evidence for nursing practice. Philadelphia: Wolters Kluwer/Lippincott Williams \& Wilkins; 2014.

[39] Reime MH, Aksnes J. [Peripheral intravenous cannula insertion: why not current guidelines tend to be followed?] Innleggelse av perifer venekanyle: Hvorfor følges ikke gjeldende retningslinjer? Sykepleien. 2002; 90(9): 34-38. http://dx.doi.org/10.4220 /sykepleiens.2002.0024

[40] Derry SJ, Pea RD, Barron B, et al. Conducting video research in the learning sciences: guidance on selection, analysis, technology, and ethics. Journal of the Learning Sciences. 2010; 19(1): 3-53. http://dx.doi.org/10.1080/10508400903452884

[41] Sandelowski M. Focus on research methods Whatever happened to qualitative description? Research in Nursing \& Health, 2000; 23: 334-340. http://dx.doi.org/10.1002/1098-240X (2000 08) $23: 4<334:$ :AID-NUR9>3.0.CO;2-G
[42] Reichertz J. The logic of discovery of grounded theory. In: Bryant A, Charmaz K, (editors). The Sage Handbook of Grounded Theory. London: Sage Publications; 2007.

[43] Bjørk IT, Kirkevold M. From simplicity to complexity: developing a model of practical skill performance in nursing. Journal of Clinical Nursing. 2000; 9 .

[44] Cappelendamm PPS, [Practical skills in nursing] Praktiske prosedyrer i sykepleien [Internet].

[45] Kristoffersen B.[Database systems] Databasesystemer. Oslo: Universitetsforlaget; 2007.

[46] Ethical principles stated on the Declaration of Helsinki (2013) [Internet]. Available from: http://www.wma.net/en/30publicati ons/10policies/b3/

[47] Houghton CE, Casey D, Shaw D, et al. Students' experiences of implementing clinical skills in the real world of practice. Journal of Clinical Nursing.2012; 22:1961-1969. http://dx. doi .org/DOI : $10.1111 /$ jocn. 12014

[48] James A, Chapman Y. Preceptors and patients - the power of two: nursing student experiences on their first acute clinical placement. Contemporary Nurse. 2009; 34(1): 34-47.

[49] Jacobson AF, Winslow EH. Variables influencing intravenous catheter insertion difficulty and failure: an analysis of 339 intravenous catheter insertions. Heart \& Lung. 2005; 34(5): 345-359. http://dx.doi.org/10.1016/j.hrtlng. 2005.04.002

[50] Helyar S, Griffiths P, Norman IJ. "The damage I could do..." - qualitative evaluation of a low-fidelity medication administration simulation that generates error as a learning experience for pre-registration nursing students. Journal of Nursing Education and Practice. 2014; 4(2):11-19. http://dx.doi .org/DOI: 10.5430/jnep.v4n2p11

[51] Thorndike EL, Rock RT. Learning without awareness of what is being learned or intent to learn it. Journal of Experimental Psychology. 1934; XVII: 1-19. http://dx.doi.org/10.1037/h0073815

[52] McGeoch JA. The configurational psychology of learning. As represented by Wheeler RH and Perkins FT. Principles of Mental Development. New.York. Crowell; 1932.

[53] Hatlevik IKR. The theory-practice relationship: reflective skills and theoretical knowledge as key factors in bridging the gap between theory and practice in initial nursing education. Journal of Advanced Nursing. 2012; 68(4): 868-877. http://dx.doi.org/10.1111/j .1365-2648.2011.05789.x

[54] Malach T, Jerassy Z, Rudensky B, et al. Prospective surveillance of phlebitis associated with peripheral intravenous catheters. Association for Professionals in Infection Control and Epidemiology. 2005; 34(5): 308-312. http://dx.doi.org/10.1016/j.ajic. 2005.10 .002

[55] Greeno JG, van de Sande C. Perspectival understanding on conceptions and conceptual growth in interaction. Educational Psychologist. 2007; 42(1): 9-23. http://dx.doi.org/10.1080/0046152 0709336915

[56] Berregan L. Simulation: an effective pedagogical approach for nursing? Nurse Education Today. 2011; 31: 660-663. http://dx. doi . org $/ 10.1016 / j$. nedt .2011 .01 .019

[57] Mansour M. Examining patient safety education in pre-registration nursing curriculum: qualitative study. Journal of Nursing Educaion and Practice. 2013; 3(12): 157-167. http://dx.doi.org/10.54 $30 /$ jnep.v3n $12 \mathrm{p} 157$

[58] Dzioba J, Cant R, Cooper S, et al. Barriers and enablers to learning during team-based clinical simulations: reflective interviews with final year undergraduate nursing students. Journal of Nursing Education and Practice. 2014; 4(10): 32-39. http://dx.doi.org/1 $0.5430 /$ jnep.v4n10p32 